\title{
EXCISION OF THE TRAPEZIUM FOR OSTEOARTHRITIS
}

\section{AT THE BASE OF THE THUMB}

\author{
G. W. VARLEY, J. CALVEY, J. B. HUNTER, N. J. BARTON, T. R. C. DAVIS
}

From Queen's Medical Centre, Nottingham, England

We have assessed the results of 34 simple excisions of the trapezium, with no additional soft-tissue procedures, in 30 patients. At a median follow-up of five years $(2$ to 22$), 16$ thumbs $(47 \%)$ were completely painfree and a further $10(29 \%)$ were slightly painful after use. Nineteen thumbs $(56 \%)$ had no functional disability, but thumb-pinch strength was reduced by about $20 \%$. No patient had painful degeneration at the scaphotrapezial pseudarthrosis.

J Bone Joint Surg [Br] 1994; 76-B:964-8.

Received 18 February 1994; Accepted 6 April 1994

Simple excision of the trapezium, with no ligament reconstruction or soft-tissue interposition, has been used for many years to treat osteoarthritis at the base of the thumb. Good results have been reported (Murley 1960; Gervis 1973; Iyer 1981), but there is little objective data on the long-term results. The recognised complications of this procedure include adduction deformity and recurrent pain at the excision-arthroplasty, although the frequency of these is unknown (Conolly and Rath 1993). It is also thought that trapeziumectomy produces weakness of the thumb.

For these reasons, many surgeons have abandoned simple excision in favour of other procedures. These include excision and soft-tissue interposition (Menon, Schoene and Hohl 1981; Amadio, Millender and Smith 1982; Dell and Muniz 1987) or ligament reconstruction (Burton and Pellegrini 1986; Weilby 1988; Nylén, Johnson and Rosenquist 1993), silastic interposition arthroplasty (Swanson, deGroot Swanson and Watermeier 1981; Swanson and de Groot Swanson 1987; Sollerman et al 1988), metacarpal osteotomy (Wilson and Bossley

G. W. Varley, FRCS, Orthopaedic Senior Registrar

J. Calvey, MB ChB, Orthopaedic Senior House Officer

J. B. Hunter, FRCS, Orthopaedic Senior Registrar

N. J. Barton, FRCS, Consultant Hand Surgeon

T. R. C. Davis, ChM, FRCS, Senior Lecturer in Orthopaedics

University Department of Orthopaedics and Accident Surgery, University

Hospital, Queen's Medical Centre, Clifton Boulevard, Nottingham NG7 2UH, UK.

Correspondence should be sent to Mr T. R. C. Davis.

(C)1994 British Editorial Society of Bone and Joint Surgery 0301-620X/94/6864\$2.00
1983; Molitor, Emery and Meggitt 1991) and trapeziometacarpal arthroplasty (Braun 1982; Cooney, Linscheid and Askew 1987; Herndon 1987; Boeckstyns et al 1989; De La Caffinière 1991). These operations are more complicated and some have unique complications such as silicone synovitis (Peimer 1987) or implant loosening (Herndon 1987). Good results have been reported for each procedure, but there is no published evidence that any is superior to simple excision.

We have performed a retrospective audit of the quality of the results of simple excision.

\section{PATIENTS AND METHODS}

We identified from the operating-theatre registers, patients who had had simple excision of the trapezium as treatment for painful osteoarthritis at the base of the thumb at Harlow Wood Orthopaedic Hospital from 1970 to 1990. Attempts were made to contact them, their case notes were reviewed and they were all invited to attend for clinical and radiological assessment. During this period other procedures, including total arthroplasty and excision of the trapezium with ligament reconstruction or silastic interposition, were used infrequently to treat the condition, but unfortunately the numbers are unavailable.

Table I. Pain at the base of the thumb after excision of the trapezium $(n=34)$

\begin{tabular}{ll}
\hline Pain & Number \\
\hline None & 16 \\
Only with or after use; does not restrict activities & 10 \\
With or after use; restricts activities & 5 \\
At rest; does not restrict activities & 0 \\
At rest; some restrictions & 1 \\
At rest; severe restrictions & 1 \\
At rest; severe restrictions and causes wakening at night & 1 \\
\hline
\end{tabular}

Assessment. Residual pain at the base of the thumb was graded as shown in Table I, and subjective impressions of stiffness and weakness were recorded as absent, mild, or severe when they interfered with hand function. The effect of residual thumb symptoms on activities of daily 
living such as ability to handle coins, hold a full can of baked beans, turn a latch key, knit and write was recorded. Each patient was asked to indicate either disappointment, satisfaction or return to normality as a result of the operation.

Clinical examination was for tenderness at the base of the thumb, range of carpometacarpal joint movement and for the presence of metacarpophalangeal hyperextension. Hand grip, thumb key and tip pinch (Hook and Stanley 1986) strengths were measured in both hands using a Jamar digital hand dynamometer. Evidence of damage to branches of the median and radial nerves was sought.

Radiographic stress views (Eaton 1979) were taken to assess the stability and condition of the scaphometacarpal pseudarthrosis. We recorded the height of the pseudarthrosis (Fig. 1; A) and the distance between the first metacarpal and the trapezoid (Fig. 1; B). Note was made of the presence of osteophytes on the distal pole of the scaphoid and the base of the first metacarpal, and we also assessed cyst formation and sclerosis at the distal pole of the scaphoid.

\section{RESULTS}

Of the 37 patients five had died and two could not be traced. We therefore report the results of 34 operations in 30 patients. Four of the patients had had another procedure performed on the contralateral thumb (three silastic replacements and one excision of the trapezium with ligament reconstruction). Twenty-eight of the patients were female; the median age at operation was 58 years (41 to 70). The operation was performed on the dominant hand in 16 and the non-dominant side in 18 . The median length of follow-up was five years (2 to 22).

Operative technique. All the excisions were performed through a dorsal incision, with no ligament reconstruction or interposition of soft tissue or silastic. The hand was then immobilised in a back-slab which held the thumb in slight palmar abduction for three to four weeks. No formal physiotherapy was prescribed.

Employment. At the time of operation, 17 patients were housewives, 10 performed light manual work, and two had office jobs. One man performed heavy manual labour. All but three of the patients returned to work within six months of operation (mean 2.5, range 1 to 6).

Residual symptoms. Of the 34 thumbs, 16 were completely painfree at follow-up (Table I), and 10 became painful with or after use, but did not restrict activities. Three thumbs were still painful at rest. The prevalence of thumb pain was not related to the length of follow-up (Table II).

In the patient's opinion, 28 thumbs were not noticeably stiff and none was sufficiently stiff to restrict activities (Table III); 14 thumbs were considered to have normal strength and 11 to have only mild weakness which did not interfere with function (Table III). There was no functional disability in 19 of the 34 thumbs, and another six reported improved thumb function. Excision of the trapezium had had no effect on function in five and caused deterioration in four. Two of the thumbs with diminished function had persistent rest pain which had been present preoperatively and was not improved by surgery. Specific functional disabilities are shown in Table IV.

Clinical examination. Of the 34 thumbs, 24 showed no residual basal tenderness. Nine had mild tenderness and only one had severe residual tenderness which interfered with function. Five thumbs showed mild paraesthesiae and tingling on the dorsum of the first web space, suggesting damage to branches of the radial nerve. Two other thumbs showed mild paraesthesiae and numbness

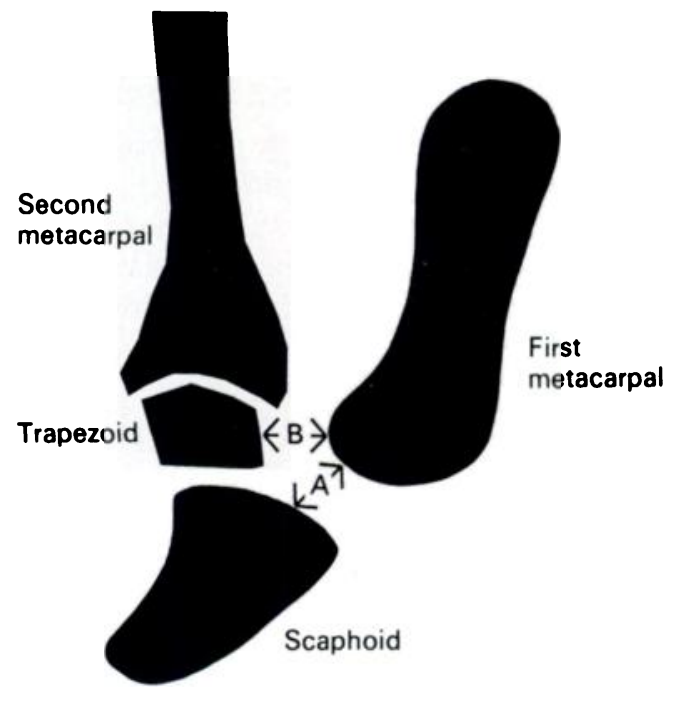

Fig. 1

Radiographic assessment of the pseudarthrosis. On stress radiographs, we recorded the distance between the scaphoid and the first metacarpal (A) and the amount of lateral subluxation (B).

Table Il. Length of median follow-up (range) compared with prevalence of pain in 34 thumbs after excision of the trapezium

\begin{tabular}{lc}
\hline Pain & $\begin{array}{l}\text { Follow-up } \\
\text { (yr) }\end{array}$ \\
\hline None & 7 (2 to 22) \\
Only with or after use; does not restrict activities & 4.5 (3 to 13) \\
At rest; restricts activities & $5.0(3$ to 14) \\
\hline
\end{tabular}

Table III. Subjective assessment of thumb stiffness and weakness in 34 thumbs after excision of the trapezium

\begin{tabular}{lll}
\hline & Stifiness & Weakness \\
\hline None & 28 & 14 \\
Mild & 6 & 11 \\
Severe & 0 & 9 \\
\hline
\end{tabular}


Table IV. Effect of excision of the trapezium $(n=34)$ on activities of daily living

\begin{tabular}{llllll}
\hline & $\begin{array}{l}\text { Handling } \\
\text { coins }\end{array}$ & $\begin{array}{l}\text { Holding } \\
\text { can }\end{array}$ & $\begin{array}{l}\text { Using latch } \\
\text { key }\end{array}$ & Knitting & Writing \\
\hline No disability & 25 & 27 & 26 & 21 & 24 \\
Improved & 1 & 2 & 1 & 2 & 1 \\
Unchanged & 0 & 1 & 1 & 0 & 1 \\
Worse & 2 & 1 & 2 & 2 & 2 \\
$\begin{array}{l}\text { Activity not } \\
\text { performed } \\
\text { with this hand }\end{array}$ & 6 & 3 & 4 & 9 & 6 \\
\hline
\end{tabular}

on the volar aspect of the thenar eminence. The paraesthesiae caused no disability. There were no painful neuromata.

The median ranges of palmar and radial abduction of the thumb were $40^{\circ}$ (20 to 70$)$ and $45^{\circ}$ (30 to 70$)$ respectively. All thumbs could be opposed and flexed sufficiently to touch the tip of the ring finger and 23 could reach the proximal digital crease of the little finger. Median metacarpophalangeal hyperextension was $15^{\circ}(0$ to 45). There were no fixed deformities at this joint.

The hand-grip and thumb-pinch strengths of the unoperated and operated thumbs of the 23 patients who had undergone unilateral surgery were compared (Table V). Both were slightly lower on the operated side. Thumbpinch and hand-grip strengths in the female patients $(28$ patients, 30 operated hands) were also compared with those of a control group of 32 women who had not

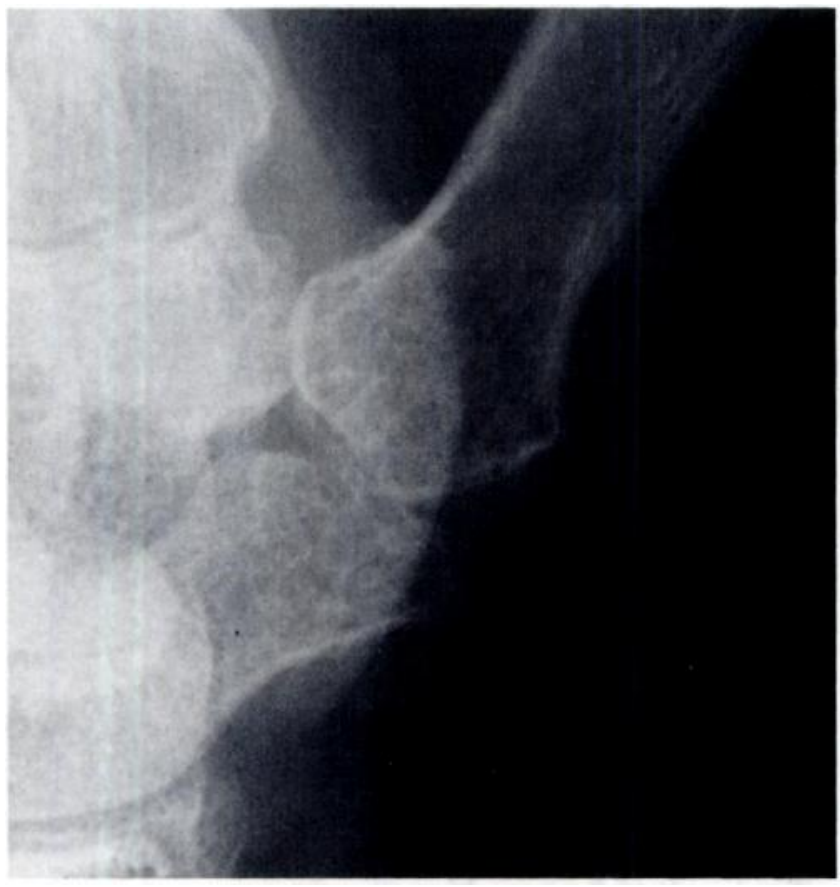

Fig. 2

Radiograph of a 59-year-old woman ten years after simple excision of the trapezium. There are small cysts in the distal pole of the scaphoid, and the patient had mild pain after use of the thumb. undergone any hand surgery and complained of no hand pain. This control group was recruited from consecutive patients admitted to Harlow Wood Orthopaedic Hospital for primary hip or knee replacement for osteoarthritis. The thumb strengths were slightly, although not significantly, lower in the operated hands (Table VI).

Stress radiographs were taken of 30 thumbs in 28 patients; these showed the average space between the scaphoid and the thumb metacarpal to be $1 \mathrm{~mm}(0$ to 7$)$, with only five greater than $2 \mathrm{~mm}$. The distance between the trapezoid and the first metacarpal was $2 \mathrm{~mm}$ or less in all but three cases. Osteophytes were present on the base of the first metacarpal of all thumbs. The preoperative radiographs, available for some but not all patients showed, however, that these had all been present before surgery and had not subsequently enlarged. In 11 thumbs there were changes in the distal pole of the scaphoid which could be attributed to degenerative changes at the pseudarthrosis, but in three patients, the stress view of the unoperated thumb showed similar sclerosis and osteophyte formation, due to scaphotrapezial osteoarthritis. Some of the changes on the operated side may therefore have been due to pre-existing degeneration. Of the remaining eight patients, five had cysts of less than $1 \mathrm{~mm}$ within the distal scaphoid with no associated osteophytes or sclerosis (Fig. 2). Two patients had sclerosis of the distal scaphoid without any other degenerative changes (Fig. 3) and the remaining patient had osteophytes of the distal scaphoid associated with soft-tissue calcification within the pseudarthrosis. The presence of 'degenerative

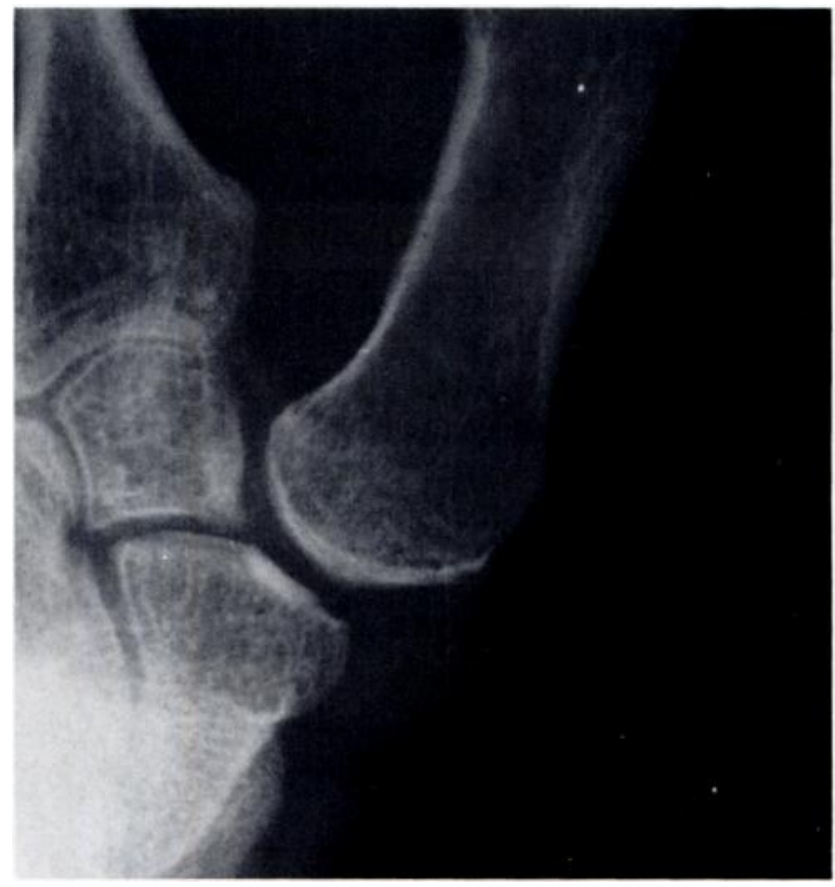

Fig. 3

Radiograph of a 45-year-old woman five years after simple excision of the trapezium. There is localised sclerosis of the distal pole of the scaphoid. Mild pain after use of the thumb did not restrict her activities. 
changes' in the distal scaphoid did not correlate with pain or the length of follow-up (Table VII).

\section{DISCUSSION}

Previous studies have not consistently assessed residual pain after surgery for osteoarthritis at the base of the thumb. Excision of the trapezium with ligament reconstruction is reported to give excellent pain relief in $92 \%$ (Burton and Pellegrini 1986) and 85\% (Weilby 1988) of cases. Using the same procedure, however, Kleinman and Eckenrode (1991) and Nylén et al (1993) described results similar to those reported for simple excision in this study. Excision with interposition of a rolled-up length of tendon gave 96\% (Menon et al 1981) and 94\% (Amadio et al 1982) pain relief. Swanson et al (1981) reported that 147 of 150 silastic trapezial implant arthroplasties were painfree but, as in many other papers, the method of assessing pain was not described. De La Caffinière (1991) reported that 9 of 13 trapeziometacarpal arthroplasties which had been followed up for more than 12 years were painfree, although four were radiologically loose. It seems

Table V. The mean thumb and hand strengths (and ranges) in 23 patients after unilateral excision of the trapezium

\begin{tabular}{lccl}
\hline & Operated side & Other side & Difference \\
\hline $\begin{array}{l}\text { Thumb-key } \\
\text { pinch }(\mathrm{kg})\end{array}$ & $3.7(1.6$ to 8.1$)$ & $4.8(1.6$ to 10.7$)$ & $-1.1(-5.2$ to +2.0$)$ \\
$\begin{array}{l}\text { Thumb-tip } \\
\text { pinch }(\mathrm{kg})\end{array}$ & $3.8(1.6$ to 8.7$)$ & $4.6(1.6$ to 7.5$)$ & $-0.8(-2.7$ to +1.2$)$ \\
$\begin{array}{l}\text { Hand-grip } \\
\text { strength (kg) }\end{array}$ & $18.3(3$ to 43$)$ & $20.2(4$ to 39$)$ & $-1.9(-10$ to +6$)$ \\
\hline
\end{tabular}

Table VI. The mean thumb and hand strengths (and ranges) in 30 women after excision of the trapezium and in an age-matched control group of 32 women

\begin{tabular}{lll}
\hline & $\begin{array}{l}\text { Trapeziectomy } \\
\text { group }\end{array}$ & $\begin{array}{l}\text { Control } \\
\text { group }\end{array}$ \\
\hline Age (yr) & $63.4(45$ to 84$)$ & $60.1(37$ to 84$)$ \\
$\begin{array}{l}\text { Thumb-key } \\
\text { pinch (kg) }\end{array}$ & $3.5(1.6$ to 7.5$)$ & $4.4(1.6$ to 9.4$)$ \\
$\begin{array}{l}\text { Thumb-tip } \\
\text { pinch (kg) }\end{array}$ & $3.7(1.6$ to 8.7$)$ & $3.9(1.6$ to 6.8$)$ \\
$\begin{array}{l}\text { Hand-grip } \\
\text { strength (kg) }\end{array}$ & $16.9(3$ to 36$)$ & $20.6(4$ to 39$)$ \\
\hline
\end{tabular}

that all types of operation produce pain relief in most patients, but the lack of a standard method of assessing pain and of any randomised prospective study makes it impossible to compare rates of pain relief. We have shown that simple excision is an acceptable treatment: $47 \%$ of thumbs became completely painfree and $30 \%$ had mild pain only after use of the thumb. This confirms the less detailed results of a previous study of simple excision of the trapezium (Iyer 1981).

It is uncertain whether simple excision causes more thumb weakness than do other operations. We recorded weaker thumb-key, thumb-tip, and hand-grip strengths than those recorded after other procedures, but they were only $23 \%, 17 \%$ and $9 \%$ respectively lower than those in the contralateral unoperated and painless hand (Table V) and not significantly different from those in the control group (Table VI). The relatively weak strengths were, therefore, partly due to general hand weakness in the tested local populations.

Thumb abduction was restricted in some of our patients, but the median result was similar to that reported after excision of the trapezium with soft-tissue interposition, ligament reconstruction or silastic arthroplasty (Amadio et al 1982; Burton and Pellegrini 1986; Pellegrini and Burton 1986).

Table VII. The presence of degenerative changes at the distal pole of the scaphoid compared with length of median (range) follow-up and the presence of residual thumb pain, by number and percentage

\begin{tabular}{llll}
\hline & $\begin{array}{l}\text { Follow-up } \\
\text { (yr) }\end{array}$ & No pain & Rest pain \\
\hline $\begin{array}{l}\text { No degenerative } \\
\text { changes }\end{array}$ & $6.1(2$ to 22$)$ & $7 / 19(37)$ & $1 / 19(5)$ \\
$\begin{array}{l}\text { Degenerative } \\
\text { changes }\end{array}$ & $5.9(2$ to 14$)$ & $4 / 11(36)$ & $2 / 11(18)$ \\
\hline
\end{tabular}

Degenerative arthritis may occur at the pseudarthrosis: seven such cases have been described at 7 to 18 years after excision of the trapezium (Conolly and Rath 1993), but the frequency of this complication was not reported. Such degenerative changes are difficult to assess; some of them may be due to pre-existing scaphotrapezial and trapeziometacarpal osteoarthritis. The available preoperative radiographs suggested that all the degenerative changes at the base of the first metacarpal, and some of those at the distal pole of the scaphoid, were caused by the pre-existing osteoarthritis. We are uncertain whether the small cysts in the distal pole of the scaphoid were due to degenerative changes at the pseudarthrosis; thumbs which showed these changes did not have a higher prevalence of residual pain or a longer period of followup. We conclude that painful degeneration of the pseudarthrosis is not common, but recognise that longer follow-up may show an increasing incidence. It has not been shown that soft-tissue interposition prevents this problem.

We conclude that simple excision of the trapezium, with no associated soft-tissue procedures, is an acceptable treatment for osteoarthritis at the base of the thumb.

No benefits in any form have been received or will be received from a commercial party related directly or indirectly to the subject of this article. 


\section{REFERENCES}

Amadio PC, Millender LH, Smith RJ. Silicon spacer or tendon spacer for trapezium resection arthroplasty: comparison of results. J Hand Surg $1982 ; 7: 237-44$.

Boeckstyns ME, Sinding A, Elholm KT, Rechnagel K. Replacement of the trapeziometacarpal joint with a cemented (Caffinière) prosthesis $J$ Hand Surg 1989; 14-A:83-9.

Braun RM. Total joint replacement at the base of the thumb: preliminary report. J Hand Surg 1982; 7:245-51.

Burton RI, Pellegrini VD Jr. Surgical management of basal joint arthritis of the thumb. Part II. Ligament reconstruction with tendon interposition arthroplasty. J Hand Surg 1986; 11-A:324-32.

Conolly WB, Rath S. Revision procedures for complications of surgery for osteoarthritis of the carpometacarpal joint of the thumb. $J$ Hand Surg [Br] 1993; 18-B:533-9.

Cooney WP, Linscheid RL, Askew LJ. Total arthroplasty of the thumb trapeziometacarpal joint. Clin Orthop 1987; 220:35-45.

De La Cafinière JY. Long-term results of total trapezio-metacarpal prostheses in osteoarthritis of the thumb. Fr J Orthop Surg 1991; 5:263-71.

Dell PC, Muniz RB. Interposition arthroplasty of the trapeziometacarpal joint for osteoarthritis. Clin Orthop 1987; 220:27-34.

Eaton RG. Replacement of the trapezium for arthritis of the basal articulations: a new technique with stabilization by tenodesis. $J$ Bone Joint Surg [Am] 1979; 61-A:76-82.

Gervis WH. A review of excision of the trapezium for osteoarthritis of the trapezio-metacarpal joint after twenty-five years. J Bone Joint Surg [Br] 1973; 55-B:56-7.

Herndon JH. Trapeziometacarpal arthroplasty: a clinical review. Clin Orthop 1987; 220:99-105.

Hook WE, Stanley JK. Assessment of thumb to index pulp to pulp pinch grip strengths. J Hand Surg 1986; 11-B:91-2.
Iyer KM. The results of excision of the trapezium. Hand 1981; 13:246-50.

Kleinman WB, Eckenrode JF. Tendon suspension sling arthroplasty for thumb trapeziometacarpal arthritis. J Hand Surg 1991; 16-A:983-91.

Menon J, Schoene HR, Hohl JC. Trapeziometacarpal arthritis: results of tendon interpositional arthroplasty. J Hand Surg 1981; 6:442-6.

Molitor PJA, Emery RJH, Meggitt BF. First metacarpal osteotomy for carpometacarpal osteoarthritis. J Hand Surg 1991; 16-B:424-7.

Murley AHG. Excision of the trapezium in osteoarthritis of the first carpometacarpal joint. J Bone Joint Surg [Br] 1960; 42-B:502-7.

Nylén S, Johnson A, Rosenquist A-M. Trapeziectomy and ligament reconstruction for osteoarthritis of the base of the thumb. J Hand Surg [Br] 1993; 18-B:616-9.

Peimer CA. Long-term complications of trapeziometacarpal silicone arthroplasty. Clin Orthop 1987; 220:86-98.

Pellegrini VD Jr, Burton RI. Surgical management of basal joint arthritis of the thumb. Part I. Long-term results of silicone implant arthroplasty. J Hand Surg 1986; 11-A:309-24.

Sollerman C, Herrlin K, Abrahamsson S-O, Lindholm A. Silastic replacement of the trapezium for arthrosis: a twelve year follow-up study. J Hand Surg 1988; 13-B:426-9.

Swanson AB, de Groot Swanson G. Reconstruction of the thumb basal joints: development and current status of implant techniques. Clin Orthop 1987; 220:68-85.

Swanson AB, deGroot Swanson G, Watermeier JJ. Trapezium implant arthroplasty: long-term evaluation of 150 cases. J Hand Surg 1981; 6:125-41.

Weilby A. Tendon interposition arthroplasty of the first carpo-metacarpal joint. J Hand Surg 1988; 13-B:421-5.

Wilson JN, Bossley CJ. Osteotomy in the treatment of osteoarthritis of the first carpometacarpal joint. J Bone Joint Surg [Br] 1983; 65-B: 179-81. 